\title{
ethic@ \\ ÉTICA DAS PESQUISAS ENVOLVENDO PESSOAS COM TRANSTORNOS MENTAIS MAIORES
}

\author{
ETHICS OF RESEARCHES INVOLVING PERSON WITH MAJOR \\ MENTAL DISORDERS
}

\author{
ALCINO EDUARDO BONELLA ${ }^{1}$ \\ (UFU/CNPq - Brasil)
}

GABRIELA FRANCO DE ALMEIDA ${ }^{2}$

(UEMG/Brasil)

LEONARDO FERREIRA ALMADA ${ }^{3}$

(UFU/Brasil)

\begin{abstract}
RESUMO
Este trabalho tem como objetivo examinar conceitualmente e de modo razoavelmente bem-informado cientificamente, a inter-relação entre vulnerabilidade mental e capacidade de decisão racional e autônoma, apresentando aspectos bioéticos relevantes, com base neste exame, mas, também, em princípios éticos consolidados, para se refletir e deliberar sobre a pertinência de pesquisas com pessoas acometidas por transtornos mentais maiores, em psiquiatria, psicologia e neurociências em geral. Depois de destacar aspectos éticos gerais da ética em pesquisa com seres humanos, o artigo examina se indivíduos com transtornos mentais maiores, a exemplo do transtorno depressivo maior, podem ser considerados efetivamente racionais, autônomos e responsáveis, se são dotados de autonomia responsável racional. Por fim, destacamos aspectos bioéticos relacionados à vulnerabilidade e racionalidade prática relacionados ao tema. Os vários aspectos teóricos e práticos destacados aqui nos parecem cruciais, e sugerem o esboço de questões e conceitos que precisam ser melhor aprofundados pelas neurociências da ética e pela ética das neurociências.
\end{abstract}

Palavras-chave: Vulnerabilidade mental; Ética da pesquisa; Transtornos mentais; Decisão racional; Autonomia; Bioética.

\footnotetext{
ABSTRACT

This paper aims to examine in a conceptual and reasonably well-informed manner from a scientific point of view, the interrelationship between mental vulnerability and rational and autonomous decision-making capacity, presenting relevant bioethical aspects, based on this examination, but also, based on consolidated ethical principles, to reflect and deliberate on the relevance of research with people affected by major mental disorders in psychiatry, psychology and neuroscience in general. After highlighting general ethical aspects of ethics in research with human
} 
beings, the paper examines whether individuals with major mental disorders, such as major depressive disorder, can be considered effectively rational, autonomous and responsible, if they are endowed with rational responsible autonomy. Finally, we highlight bioethical aspects related to vulnerability and practical rationality related to the theme. The various theoretical and practical aspects highlighted here seem crucial, and suggest the outline of questions and concepts that need to be further explored by the neuroscience of ethics and the ethics of neuroscience.

Keywords: Mental vulnerability; Ethics of research; Mental disorders; Rational decision; Autonomy; Bioethics.

\section{Introdução}

Este trabalho tem como objetivo examinar conceitualmente e de modo razoavelmente bem informado cientificamente, a inter-relação entre vulnerabilidade mental e capacidade de decisão racional e autônoma, apresentando aspectos bioéticos relevantes, com base neste exame, mas, também, em princípios éticos consolidados na literatura filosófica e em práticas institucionais recentes, para se refletir e deliberar sobre a pertinência de pesquisas com pessoas acometidas por transtornos mentais maiores em psiquiatria, psicologia e neurociências em geral. Nossa hipótese principal é que a pertinência ética do envolvimento de pessoas com transtornos, em pesquisas, dependerá em grande parte de se compreender melhor o desafio da vulnerabilidade como um impedimento às pesquisas ou terapias, de modo que, em certos casos, a vulnerabilidade psíquica seja suficiente como razão contrária à aceitação do envolvimento e mesmo da vontade do paciente em participar, mas, em outros casos, provavelmente, o paciente, avaliando sua situação e a pesquisa/terapia proposta e tomando sua decisão, deve ser respeitado em sua opção, mesmo se está acometido por um transtorno. Aspectos gerais sobre a ética da pesquisa estão em destaque na parte 1 (A ética da pesquisa com seres humanos); aspectos específicos sobre racionalidade, autonomia e transtornos maiores, à luz das neurociências e da filosofia das neurociências, estão nas partes 2 (Neurociências, racionalidade e autonomia) e 3 (Racionalidade, autonomia e transtornos mentais); por fim, considerações específicas de Bioética, à luz dos destaques organizados em 1, 2 e 3, estão na parte 4 (Capacidade de decidir, vulnerabilidade e bioética), que encerra nossa contribuição para este dossiê.

\section{A ética da pesquisa com seres humanos}

A participação voluntária de pessoas em pesquisas é uma das formas mais importantes e valiosas de adquirirmos conhecimento médico na área 
da saúde. É um dos meios de se buscar ajuda aos que mais necessitam de cuidados de saúde como as que são acometidas de doenças graves para as quais não há ainda bons tratamentos ou remédios. Todavia, o próprio conhecimento que se adquire com a participação de voluntários, desde que bem esclarecidos e livres de coerção ou manipulação, é algo como um valor impessoal, seja quais forem os benefícios aos participantes e agentes em protocolos de pesquisa. Há também ganhos em termos de saúde pública e aprimoramento cultural, para a sociedade como um todo. Outro benefício é aquele propiciado às próprias instituições de pesquisa e seus agentes principais, os cientistas que desejam conhecer e que desejam desenvolver a pesquisa clínica. Todavia, um dos benefícios mais almejados com as pesquisas com seres humanos é aquele gerado diretamente aos participantes voluntários, muitas vezes pessoas acometidas pelos males que se quer aliviar ou superar.

As pessoas participantes da produção do conhecimento são parte fundamental da instituição científica em seu sentido amplo, que é mantida e aperfeiçoada com a tal voluntariedade, e assim, tais pessoas estão contribuindo com o bem-estar não apenas de si mesmas, mas de outros, e para muitos, isso é um benefício, estar a ajudar os outros. Outro benefício é obter conhecimento de si, pois as pessoas que participam podem ter um feedback do que foi descoberto no projeto em que participou, em parte algo relacionado a si mesma. Elas também terão interação com profissionais das áreas de saúde e da ciência, e com outros participantes, muitas vezes. Também benéfico ao participante, e mais importante, é o cuidado clínico que normalmente recebe, se necessita, ou se é o que, exatamente, está em estudo. (BEAUCHAMP, 2019; BONELLA, 2020; HUGHES et. al., 2010).

$O$ padrão normativo em pesquisas com seres humanos costuma ser sintetizado nos quatro princípios do respeito pela autonomia, da não maleficência, da beneficência e da justiça (BEAUCHAMP; CHILDRESS, 2013). Para respeitar-se a autonomia se defende, em uma já consolidada tradição moral e jurídica, o consentimento livre e esclarecido dos participantes. Daí a tripartite condição para um consentimento válido, em pesquisa: que os participantes tenham adequada informação e oportunidade para digerir e deliberar sobre ela; que eles tenham competência ou capacidade psíquica suficiente para reter tais informações e comunicar suas percepções e decisões aos pesquisadores; que tome suas decisões livre de coerção, manipulação ou indução indevida (HUGHES et. al., 2010; BEAUCHAMP; CHILDRES, 2013; GATHER; VOLLMANN, 2013). Essas condições implicam, dada a experiência negativa em muitos contextos de exploração das pessoas em pesquisas e terapias, preocupação explícita e cuidado mais rigoroso com a vulnerabilidade de pessoas que 
podem não estar em condições mínimas nem com capacidade para dar tal consentimento.

Dentre as razões favoráveis ao envolvimento de pessoas com diagnóstico de transtorno mental, em especial de depressão maior, em pesquisas médicas, figuram tradicionalmente os seguintes fatos: de que em muitas situações tal participação é do melhor interesse da própria pessoa, ao menos em pesquisas que incluem poucos riscos e prometem benefícios aos participantes; de que a expressão da vontade dos participantes ou de seus representantes deve ser respeitada, ao menos nos contextos de tomada de decisão esclarecida e livre de coação ou coerção. Dentre as razões contrárias estão: a possibilidade e o receio de erros no diagnóstico global do paciente (ou de seus representantes), especialmente quanto à suas capacidades de discernimento e decisão; o risco de enfraquecimento da proteção contra exploração e danos dada a vulnerabilidade da pessoa com transtorno mental, especialmente quando da depressão maior, já que as dificuldades residirão exatamente na natureza e realização do processo de tomada de decisão racional, nestes casos.

Considerando a vontade esclarecida e livre das pessoas como razão em favor do direito à recusa ou aceitação de terapias e pesquisas envolvendo a si, e a vulnerabilidade humana especialmente presente em transtornos mentais maiores, algo que comumente se entende como afetando direta e negativamente a capacidade de se entender e decidir racionalmente, como forte razão contrária, a reflexão bioética bem informada cientificamente deve tentar destacar aos pesquisadores, gestores de instituições científicas, comitês de ética e à sociedade como um todo, aspectos relacionados à vulnerabilidade decisória e à autonomia, para a ética das pesquisas em neurociências com pacientes acometidos de doenças mentais, em especial com pessoas com transtornos mentais maiores. Por outro lado, a autonomia, que diz respeito à prática do consentimento e à tomada de decisões esclarecidas e voluntárias, e que possam também ser vistas por terceiros como decisões condizentes com o interesse próprio destas pessoas, demanda eticamente respeito ao que tais pacientes escolhem e à sua relativa capacidade de escolha. Uma das questões cruciais colocadas aqui pode ser formulada da seguinte maneira: indivíduos com transtornos mentais maiores, a exemplo do transtorno depressivo maior, podem ser considerados efetivamente autônomos, responsáveis e racionais, ou ainda, seriam eles dotados de suficiente autonomia responsável e racional? 


\section{Neurociências, racionalidade e autonomia}

Nos termos de Buss e Westlund (2018), um dado indivíduo pode ser concebido como um agente, e mais especificamente como um agente autônomo se, e somente se, suas ações morais expressam autogoverno. Essa definição deixa margens para uma questão adicional, não negligenciada por Buss e Westlund (2018), a saber: o que é assegurado a um indivíduo capaz de se autogovernar? Ora, sabemos que o autogoverno nem (i) induz a um aumento no leque de nossas possibilidades, nem (ii) guarda relações com o surgimento de opções mais interessantes e/ou agradáveis. Da mesma forma, autogoverno parece não implicar (iii) a capacidade de reconhecer as diferenças entre o certo e o errado. Se é verdade que o autogoverno não implica a capacidade de discriminar, em nível moral, o certo do errado, será que, ainda assim, há alguma relação importante entre autonomia, racionalidade e responsabilidade?

Pensamos que, se é verdade que o autogoverno não implica necessariamente a capacidade de discriminar certo de errado, é verdade também que a autonomia, a responsabilidade e a racionalidade guardam entre si uma relação de codependência. Tentemos clarificar melhor as condições que um indivíduo deve atender para que ele possa ser legitimamente considerado como responsável pelo conjunto de seus estados mentais e comportamentais. Vamos assumir por ora que 'agente' é um indivíduo com capacidade de agir, isto é, dotado do poder de perpetrar uma ação ou um conjunto de ações com vista a um determinado fim a partir de suas próprias forças mentais e comportamentais. Será que, por trás deste conceito de agência, está mais ou menos implícito que não há nada ou alguém que possa interferir na capacidade que o agente tem de ser a causa de uma prévia deliberação?

É escusado lançar mão de referências filosóficas e científicas para desmistificar um sentido inflacionário de agência. A depender do sentido de agência que adotemos, é possível - e, mais do que isso, plausível defender que não nos governamos a nós mesmos plenamente. A autoridade que julgamos ter sobre as nossas ações não necessariamente implica um poder real e pleno: se é verdade que um agente se determina a agir, e se é verdade que um agente traz consigo as condições mentais e comportamentais para tanto, também é verdade que muitas são as 'forças' e influências que operam para além da sua autoridade, isto é, de seu consentimento e mesmo de sua (sen)ciência (BUSS; WESTLUND, 2018).

Entre teorias psicológicas tão díspares quanto a psicanálise e 0 behaviorismo, prevalece o consenso de que circunstâncias passadas e presentes determinam o nosso comportamento sem que tenhamos 
controle. Segundo Buss e Westlund (2018), algumas das forças que nos movem a agir "não afetam meramente as ações que escolhemos realizar, nem como nos governamos ao fazer essas escolhas". Antes, essas forças "nos influenciam de uma forma que zomba de nossa autoridade para determinar nossas próprias ações. Elas minam nossa autonomia". Será esse o caso dos transtornos mentais maiores, como propõe Ratcliffe (2013, p. 574), para quem no mínimo a depressão envolve uma experiência fenomenológica de diminuição de livre-arbítrio? Ou, antes, estariam marcadores neurais minimizando a agência de indivíduos com transtornos mentais maiores para além de uma experiência fenomenológica?

Buss e Westlund (2018) propõem que nossas ações são movidas pelo embate entre dois grupos antagônicos de influências, a saber: (i) as influências que contribuem para 'minar' nossa autonomia, no sentido de interferir nas decisões, intenções e/ou vontades dos agentes, e (ii) as forças autogeradas e motivadoras dos processos mentais/comportamentais que se expressam como autogoverno. Esse embate é, segundo Buss e Westlund (2018), a gênese do problema filosófico da autonomia. Trata-se, naturalmente, de um dos mais espinhosos problemas em filosofia, sobretudo por sua natureza interdisciplinar e pela possível dependência que temos de neurotecnologia para um dia vislumbrarmos uma resolução mais efetiva.

A discussão teórica sobre as características que mais essencialmente definem o que é a agência encontra obstáculos importantes na presença de fatores psíquicos complexos, como desejos, impulsos e, dentre tantos outros, compulsões. Em que sentido poderíamos dizer que esses motivos (desejos, impulsos, compulsões etc.) são externos ao agente? Como podemos dizer que somos movidos por forças internas? Como explicar a dissociação entre forças antagônicas que, no entanto, são geradas pelo mesmo sistema, o do agente?

Por motivos que explicitamente desconhecemos, o termo liberdade (freedom) foi retirado do DSM-V, a atual edição do Manual Diagnóstico e Estatístico de Transtornos Mentais. Nossa hipótese é a de que é provável que o termo freedom, tenha sido o 'bebê' que foi eliminado junto com 'a água do banho', pois, na definição do DSM-IV, o termo freedom aparece em um contexto que, de maneira geral, foi eliminado no DSM-V. Na seção do DSM-IV dedicada à definição de transtorno mental, temos que transtornos mentais devem ser entendidos "como uma síndrome ou padrão psicológico ou comportamental clinicamente significativo que ocorre em uma pessoa", e que estão associados "ao risco de sofrer morte, dor, deficiência ou uma perda importante de liberdade". Na definição do DSM$V$, houve a intenção de eliminar a noção de dano, risco etc., e transtornos 
mentais passaram a estar associados a um "sofrimento significativo ou deficiência em atividades sociais, ocupacionais ou outras atividades importantes". Ainda que, do ponto de vista do que requer a teoria da psiquiatria para definição de transtornos mentais, exista uma diferença importante entre (i) oferecer risco a si mesmo e (ii) não oferecer risco a si mesmo, para nossos propósitos, interessa-nos apenas o flerte na relação entre transtornos mentais e autonomia (liberdade).

Com efeito, essa relação está estabelecida no DSM-IV e, acreditamos, permaneceria estabelecida no DMS-V se os proponentes da definição de transtornos mentais não incluíssem em um mesmo plano conceitual as noções de 'colocar-se em risco' e de 'liberdade'. Poderia estar presente no DMS-V, sem nenhum prejuízo na reformulação de transtorno mental, a ideia, presente no DSM-IV, de que uma importante perda de liberdade (sentimento de?) constitui uma das principais características dos transtornos mentais.

Meynen (2010) parece ser claro em sua exposição acerca da relação entre transtornos mentais e autonomia (ou liberdade, em seus termos). Em sua tentativa de explorar as relações entre transtornos mentais e livrearbítrio, Meynen (2010) busca advogar a tese consoante a qual transtornos mentais constituem condições que, não raramente, comprometem o livrearbítrio, e, em consequência, reduzem a responsabilidade moral. Em psiquiatria forense, lembra Meynen (2010, p. 429), é comum que se busque minimizar a responsabilidade moral a partir do argumento de que o livrearbítrio é comprometido por transtornos mentais. Para tornar mais claros os seus argumentos, Meynen (2010) discute três sentidos de livre-arbítrio, e afirma, na linha de Ratcliffe (2013), que devemos considerar os relatos de pessoas que vivenciaram transtornos mentais.

Com base em Walter (2001), Meynen (2010) propõe a existência de três características essenciais para qualquer teoria do livre-arbítrio, sem deixar de reconhecer, também em sintonia com Walter (2001), que, entre as diversas teorias do livre-arbítrio, não há consenso quanto a simultânea presença desses três aspectos: (i) capacidade de agir de outra forma da que agiu, o que quer dizer, presença de possibilidades alternativas de ação; com efeito, se não se pode escolher entre alternativas de ação porque se está completamente determinado a agir de uma maneira em especial (seja por ditames divinos, seja por questões neurais), então não se pode dizer que um agente seja livre; (ii) a ação livre consiste na capacidade de agir (ou selecionar opções de ação) com base em razões inteligíveis, o que quer dizer que uma das condições de possibilidade para a realização de uma ação voluntária é que ela seja realizada com base em razões e que ninguém pode ser condenado por, por exemplo, bater em outra pessoa durante uma crise 
epilética (o que dizer, mais ainda, de algumas das ações que tipificam um transtorno mental maior?); (iii) uma ação livre pressupõe que o agente seja o originador das suas próprias ações, isto é, a causa efetiva da ação, e não apenas um mero executor, como ocorre com alguém que age sob efeito de algum fator, condição ou substância e, nesse sentido, não pode ser considerado o autor genuíno de sua própria ação.

Se todos, alguns ou nenhum desses sentidos é efetivamente pertinente ou decisivo para o conceito de livre-arbítrio e para a responsabilidade moral é questão de grande e intenso debate entre os filósofos e neurocientistas dos mais variados espectros teóricos e programas de pesquisa empírica.

\section{Racionalidade, autonomia e transtornos mentais}

Uma das investigativas mais importantes a destacar pode ser inicialmente formulada da seguinte maneira: indivíduos com transtornos mentais maiores, a exemplo do transtorno depressivo maior, podem ser considerados efetivamente autônomos?

Dada uma concepção de autonomia que parece normalmente pressuposta - no caso, a capacidade de agir deliberadamente a partir de razões internas - temos que a definição de autonomia que nos interessa (autonomia pessoal ou moral) não subsiste em separado das noções de responsabilidade e racionalidade. Seria então importante inquirir em que sentido a noção de autonomia que está por trás da nossa questão central envolve as noções de responsabilidade e de racionalidade. Cumpre adiantar, com base em razões que sustentaremos ao longo desse texto, que, se considerada em seus caracteres implícitos e explícitos, a questão poderia ser bem formulada da seguinte maneira: indivíduos com transtornos mentais maiores, a exemplo do transtorno depressivo maior, podem ser considerados efetivamente responsáveis e racionais, ou ainda, são dotados de tal autonomia responsável racional?

Transtornos graves, a exemplo dos transtornos mentais maiores, usualmente envolvem algum tipo de deficiência/lacuna perceptiva, afetiva e/ou de raciocínio. Ao que parece, essas deficiências/lacunas podem ser concebidas como características que, de uma forma ou de outra, minimizam a autonomia, a responsabilidade, a racionalidade e, também, a coerência e o senso de unificação da personalidade. Essa é, por exemplo, a concepção de Eugen Bleuler (1911) acerca da esquizofrenia, termo cunhado por ele para tipificar um transtorno mental que concebeu como sendo caracterizado pela desintegração do funcionamento unitário e coerente de diferentes dimensões psíquicas, o que implica a dissolução da autonomia, da 
racionalidade e da responsabilidade. Essas características e implicações são supostamente instanciadas nos inúmeros outros transtornos psiquiátricos em que também verificamos a minimização dos substratos psíquicos/neurofisiológicos que constituem condição de possibilidade para autonomia, racionalidade e responsabilidade: é o que ocorre nas adicções, na síndrome de Tourette, no transtorno obsessivo-compulsivo e, naturalmente, nos transtornos depressivos maiores.

No que concerne às neurociências da ética, a minimização da autonomia racional, da responsabilidade, da racionalidade e da personalidade coerente e unificada está associada a importantes desafios filosóficos sobre autonomia e tomada de decisão (Edwards, 1997; Radoilska, 2012; Sadler, Fulford; van Staden, 2015). No que concerne, por sua vez, a uma ética das neurociências, essas mesmas características estão associadas a questões filosóficas importantes sobre um suposto uso de métodos coercitivos e de estratégias manipuladoras, dado que, na ausência de um pleno sentido de autonomia, racionalidade, responsabilidade e personalidade, qualquer terapia ou pesquisa envolvendo pessoas com transtornos mentais maiores pode configurar um método coercitivo (Radden, 2019).

Em uma discussão acerca das relações entre racionalidade e sanidade, e sobre o papel de juízos de racionalidade no entendimento de transtornos psiquiátricos, Bortolotti (2013), discutindo transtornos psiquiátricos maiores, se pergunta, com base em questões anteriormente suscitadas por Szasz (1997): qual a relação entre a racionalidade e a sanidade? Será que podemos estabelecer uma relação de equivalência entre insanidade e irracionalidade? Será que podemos julgar a racionalidade do comportamento alheio? Será que devemos, ainda de acordo com Szasz (1997), como demonstra Bortolotti (2013), aceitar a suposição de que os chamados 'insanos' sejam inimputáveis, isto é, que não devam ser responsabilizados por sua ação em nome de uma alegada irracionalidade e falha de autonomia?

Essa é, segundo o clássico texto de Szasz (1997), a visão jurídica do transtorno mental. Na visão que Szasz (1997) denomina de psiquiátrica, a insanidade é uma doença, e a qual (i) decorre de um mau funcionamento neurobiológico e (ii) se expressa por meio de um comportamento desviante: nesse âmbito, a irracionalidade não participa do diagnóstico e tampouco da classificação dos transtornos psiquiátricos.

Na visão jurídica, por sua vez, aponta Szasz (1997), transtornos psiquiátricos são mentais e comportamentais, e, diferentemente do que verificamos na visão neurobiológica, a irracionalidade desempenha um papel fundamental na deteç̧ão de transtornos maiores. Segundo a 
perspectiva jurídica de transtornos mentais, a doença mental não configura propriamente uma doença, mas, antes, uma falha significativa de racionalidade e autonomia (Edwards, 1981; Bortolotti, 2013, p. 480-481).

Ainda no ano de 1981, Edwards propõe que: a autonomia pressupõe saúde mental, e a doença mental, por sua vez, consiste, em parte, na perda dessa autonomia. A partir da definição de Edwards (1981, p. 312) de 'transtorno mental' como o conjunto de desvios mentais e/ou comportamentais indesejáveis que acarretam uma incapacidade extrema e prolongada (i) de se conhecer e (ii) de lidar de forma racional e autônoma consigo mesmo e com o ambiente social e físico, podemos concluir a existência, no cenário acadêmico, da concepção de insanidade mental como ausência de autonomia, como irracionalidade e, ademais, como irresponsabilidade extrema e prolongada. Ato contínuo, Edwards (1981, p. 312) propõe que a saúde mental inclui normalidades mentais e comportamentais e também anormalidades ocasionais, as quais contribuem para que nos seja permitido "conhecer e lidar de forma racional e autônoma conosco e com nosso ambiente social e físico". Dito de outra maneira: saúde mental é condição de possibilidade de racionalidade prática e responsabilidade. Essa tese foi compartilhada, de uma ou de outra forma, por Breggin (1974, 1975), Elglehardt Jr. (1973), Fingarette (1972) e Moore (1975).

A definição de 'saúde e transtorno mental' por Edwards (1981) é de fato esclarecedora para um entendimento ulterior da relação entre transtornos maiores, autonomia e racionalidade. Este é o norte em torno do qual giram todos aqueles que, como Edwards (1981), Breggin (1974, 1975), Elglehardt Jr (1973), Fingarette (1972) e, dentre tantos outros Moore (1975), pressupõem que saúde mental envolve autonomia racional.

Quando procede à dissociação entre a normalidade e a anormalidade, ou ainda, entre o desejável o indesejável em termos de mental e comportamental, Edwards (1981) está propondo uma relação estreita entre os níveis do mental e do comportamental, e é com base nos pilares estabelecidos por essa relação que nos sentimos ulteriormente autorizados a discutir se transtornos mentais maiores ferem ou não a nossa autonomia e nossa racionalidade.

A proposta de Edwards (1981) para o conceito de autonomia aponta para a concepção de que estados mentais - como pensamentos, desejos e sentimentos - são objetivamente mensuráveis no tanto quanto se manifestam por "alterações e atividades corporais observáveis". Sua definição de autonomia é dependente das relações que estabelece entre mental e comportamental: autonomia é a capacidade de fazer suas próprias escolhas, administrar seus próprios assuntos práticos e ser capaz de 
gerir/ter a responsabilidade por sua própria vida, por sua posição e seus deveres (Edwards, 1981, p. 312).

Diante de sua definição de autonomia, podemos nos perguntar: a autonomia pressupõe a racionalidade? Vejamos. A racionalidade, segundo Edwards (1981, p. 314-315), envolve pelo menos 7 (sete) características, quais sejam: (i) capacidade de distinguir fins aspirados de meios necessários para atingir fins, de onde deve se seguir a habilidade de discriminar quais são os processos e os comportamentos necessários para que levemos à consecução um ou mais objetivos voluntariamente idealizados; (ii) capacidade de efetuar raciocínios lógicos e, em simultâneo, evitar crenças logicamente contraditórias; (iii) habilidade de alimentar suas próprias crenças em fatos que se apoiam em evidências e, em simultâneo, evitar crenças factuais que são falsificadas (e não meramente falseáveis) pela experiência; (iv) posse e capacidade de dar razões legítimas para os próprios comportamentos e crenças; (v) possuir raciocínio argumentativo claro e inteligência e, em simultâneo, não pensar de maneira confusa e nutrir crenças absurdas; (vi) habilidade de nutrir imparcialidade e justeza epistêmicas e morais na análise, juízo e adoção de crenças; (vii) mover-se por valores autônomos (e, portanto, não-heterônimos), isto é, adquiridos e mantidos em um contexto de liberdade, de esclarecimento e de imparcialidade.

Essas características indicam que a definição de racionalidade proposta por Edwards (1981, p. 315), diz respeito ao modo 'como' apreendemos e 'como' conhecemos o mundo, e não 'o que' apreendemos e 'o que' sabemos, de modo que racionalidade é o oposto de irracionalidade, e não de ignorância e/ou estupidez. Com Edwards (1981), nós nos comprometeríamos com uma definição de saúde mental como algum tipo de desvio ou ausência de racionalidade, e, se assumimos que a autonomia implica racionalidade num sentido muito elevado e exigente, parece que se deve concordar com Edwards (1981) quanto ao fato de que saúde mental não prescinde de níveis importantes de autonomia racional. Quando se diz que a ausência de saúde mental envolve um tipo de desvio/lacuna/ausência de estados mentais/comportamentais específicos, se está querendo dissociar a ausência/lacuna/desvio que inere à autonomia racional dos desvios/ausências/lacunas que decorrem de imoralidade, ausência de empatia e/ou sentimento de compaixão etc.

Uma dificuldade adicional é: quanto de racionalidade é necessário para que um indivíduo se revista de sanidade? Quando pensamos a relação entre transtornos mentais, responsabilidade, racionalidade e sanidade, devemos considerar as evidências de que transtornos psiquiátricos maiores interferem na capacidade neurocientífica de avaliar a capacidade de tomada 
de decisão, já que, como muito bem afirmam Hindmarch, Hotopf e Owen (2013), "a psicopatologia é o extremo de uma dimensão que inclui a normalidade". Também conforme demonstram, existem critérios supostamente fidedignos para avaliar o que chamam de capacidade de tomada de decisão nos transtornos mentais maiores, a saber: (i) compreensão, (ii) apreciação, (iii) raciocínio e (iv) capacidade de expressar uma escolha. Há muitas dúvidas entre aqueles que se debruçam sobre a depressão acerca da capacidade que indivíduos com depressão têm de (i) tomar decisões no seu tratamento ou de (ii) participar em pesquisas.

Critérios para definir a capacidade que indivíduos com transtornos mentais maiores têm para tomar decisões podem ser estabelecidos de uma forma mais rigorosa a partir do modelo de Grisso e Appelbaum (1998): (i) capacidade para idealizar uma escolha a partir da consideração dos contrários; (ii) habilidade cognitiva para compreensão de informações relevantes para tomar decisões em relação aos rumos do tratamento; (iii) habilidade de apreciar plenamente a significação das informações que dizem respeito à sua saúde e aos rumos do tratamento no que diz respeito à sua própria situação, (iv) capacidade de racionar com base nas informações relevantes recebidas, o que envolve a capacidade de uma deliberação final em um processo lógico de pesar diferentes razões para diferentes opções. No âmbito desse modelo - conhecido como modelo de quatro habilidades - nenhum paciente poderia ser considerado autônomo no sentido que aqui usamos, isto é, alguém dotado de autonomia, racionalidade, responsabilidade e sanidade, sem a plena posse das recémmencionadas quatro habilidades.

Estamos de acordo com Hindmarch, Hotopf e Owen (2013), para quem os transtornos mentais maiores constituem fatores gerais de risco para nossa capacidade de tomar decisões por motivos que não apenas a perda na integridade de compreensão. Antes, mudanças na estrutura afetiva e cognitiva do indivíduo são fatores a ser considerados.

É de fato muito complexo computar em termos objetivos o que conta como os motivos que geram uma perda na capacidade de tomar decisões, apesar de não termos dúvidas quanto a existência desses motivos. Não há dúvidas, no entanto, que, de alguma maneira importante, transtornos mentais maiores, especialmente em momentos de crise, envolvem a ruptura de caracteres psíquicos indispensáveis para uma idealizada capacidade de tomar decisões. O desenvolvimento de pesquisas empíricas nas ciências do cérebro ainda está por nos esclarecer melhor quais são as características que distinguem a capacidade que temos ou não de autonomia, racionalidade e responsabilidade, e em que sentido e/ou em 
qual intensidade as alterações de nossas capacidades cognitivas e afetivas contribuem para a minimização da capacidade que temos de autogoverno.

Acreditamos que concepções mais básicas e mais simples de racionalidade prática sejam suficientes para considerarmos alguém como um sujeito racional e capaz de decidir, e, assim, mesmo pessoas com transtornos mentais maiores podem ainda ter sua autonomia respeitada, seja para se retirar, seja para se manter em um projeto de terapia ou de pesquisa, dependendo da magnitude de sua capacidade de deliberar. Voltemos então à teoria ética da autonomia em contextos de pesquisa com pessoas humanas vulneráveis.

\section{Capacidade de decidir, vulnerabilidade e bioética}

Os aspectos emocionais e cognitivos envolvidos em momentos de fragilidade humana maior, como nos tratamentos médicos sem perspectiva de cura ou no caso dos transtornos mentais maiores, sugerem que as funções de julgamento e decisão de alguém a respeito do que vem a ser melhor para si mesmo estão normalmente enfraquecidas. Isso coloca a pessoa sob o risco de decidir mal ou de sofrer pressão e submissão ao que Ihe é sugerido por clínicos e pesquisadores. A pessoa pode de fato estar incapacitada para escolher de modo significativamente voluntário, e, assim, receber orientação médica independente, assim como apoio dos familiares, para tal, pode ser-Ihe necessário e benéfico. Tal orientação e interferência de terceiros também pode, porém, ser prejudicial, simplesmente porque a vontade de outros pode se sobrepor à do próprio paciente e ao seu melhor interesse (BEAUCHAMP; CHILDRESS, 2013). Também pode acontecer de a fragilidade ser intensificada exatamente pelas relações assimétricas de poder e saber: de um lado a equipe médica, além da família ( $e$, em alguns lugares, comissões de ética, em questão decisões vitais), de outro, o paciente normalmente vulnerável (CORDEIRO, 2013; NYS, 2016).

Várias informações são repassadas para o paciente, e modos variados de comunicação destas informações podem ser adotados, podendo gerar viés em favor de que ele escolha uma determinada opção ao invés de outra, às vezes apressadamente, às vezes não, mas com manipulação (GATHER; VOLLMANN, 2013). Como parte do problema das relações assimétricas, o vínculo de confiança, em certa medida, parece contribuir para que uma pessoa se torne vulnerável a outra, pois quanto mais uma pessoa confia em outra, mais chance tem de ser influenciada indevidamente por esta (NYS, 2106). Por outro lado, que haja vínculo de confiança mais sólido entre médico e paciente é também uma garantia para que as pessoas tomem suas decisões de modo seguro (BEAUCHAMP; CHILDRESS, 2013). 
Podemos considerar a delimitação de que pessoas vulneráveis por razões intrínsecas à sua condição física ou psíquica individual são aquelas que: não possuem competência ou capacidade de proteger a si mesmas de danos, ao dar ou retirar o seu consentimento/assentimento à participação em pesquisa ou terapia; tem o seu consentimento comprometido por influências (indevidas) de terceiros, influências que não são, em princípio, detectadas por ela, dada a fragilidade mental ou física no processo de obtenção do consentimento; a condição de saúde do participante o torna uma vítima potencial de dano como por exemplo, por sua idade, doença, inabilidade física ou mental. (HUGHES et. al., 2010; BEAUCHAMP; CHILDRES, 2013). No caso da incapacidade ou incompetência para tomar decisões voluntárias e livres no sentido prático acima, é importante considerar o que podemos tratar como uma habilidade básica e simples de deliberar praticamente, algo que encontramos em Hughes e seus colaboradores (2010), mas que aqui adotamos com algumas pequenas modificações:

(i) compreender a informação relevante relativa à pesquisa/terapia e à sua própria condição, e manter essa compreensão por ao menos um certo período de tempo necessário para se manter o consentimento esclarecido;

(ii) conseguir ponderar/sopesar sobre tal informação e sobre os prós e contras à sua participação;

(iii) tomar decisões com alguma independência do pesquisador/clínico ou capaz de considerar o risco de estar sob indução indevida;

(iv) capacidade de comunicar seu consentimento ou recusa de modo pessoal ou minimamente articulado.

Enquanto a vulnerabilidade, no contexto de decisão racional, é compreendida como fragilidade desta capacidade decisória, em razão da própria condição de saúde, com presença de maior dificuldade para defender seus melhores interesses, e com exposição a maior risco de ser manipulado, o grau de racionalidade, autonomia e responsabilidade que possa ser aferido, clínica e cientificamente, é de suma relevância para se evitar o outro lado da manipulação e exploração, o de excluir pura e simplesmente sujeitos vulneráveis acometidos de transtornos mentais mas que queiram participar de pesquisas ou esquemas terapêticos ainda em estudo, inclusive arriscadas. Um destaque a ser feito, por exemplo, é que a incapacidade para decidir de modo racional e autônomo pode ser temporária e os pesquisadores, clínicos e familiares podem ainda buscar diminuí-la para que o paciente esteja em condições melhores de decidir.

Nos casos de demência, por exemplo, no início da doença em geral o paciente consegue perceber a perda de si e a própria perda da capacidade de decidir, além de compreender que o prognóstico é ruim, sem 
possibilidade de cura, o que torna o processo mais delicado, mas também bem definido factualmente. Alguns, diante da situação, resolvem pedir ajuda médica para morrer e tal pedido suscita problemas importantes. Primeiro, o sofrimento é um elemento de acentuação da vulnerabilidade, isto é, põe-se em questão se o paciente, vivenciando sofrimento e não tendo opções de cura, não faz o pedido com pouca ou nenhuma liberdade. Dado que a boa prática médica visará mitigar o sofrimento, não é incomum se pensar que a vulnerabilidade por si mesma também deve ser amenizada pela equipe de cuidados, por exemplo, ampliando as perspectivas de se lidar com o sofrimento e com as dificuldades cognitivas.

Por outro lado, apesar de tal ampliação e da maior atenção da equipe às capacidades do paciente, a realidade do sofrimento psíquico, mesmo após a amenização do sofrimento físico (dor e desconforto), coloca questões sobre como lidar com os muitos aspectos biográficos, psicológicos e cognitivos, do sofrimento específico deste paciente sob cuidados. Tal coisa pertence àquela pessoa, o que parece ser também uma razão suficiente para levar a sério seus desejos; veja que sua doença degenerativa está no início e sua capacidade de decisão competente parece estar razoavelmente preservada. Gather e Vollmann sugerem uma atenção ao histórico do paciente e seu entorno (e relações) visando facilitar a compreensão dos valores pessoais fundamentais do paciente. Algo similar pode ser tentado no caso de transtornos mentais maiores.

Outro ponto importante, especialmente no caso de um paciente no início de demência, diz respeito ao papel do médico principal do paciente. Nesse processo, a começar da realização de um diagnóstico confiável, excluindo causas tratáveis e reversíveis, parece relevante que o médico seja quem avalie se um desejo do paciente não é apenas transitório, ou se não é resultado de depressão maior associada, que poderia ser tratada. Psicologicamente, expressar desejo de morrer, por exemplo, poderia ser uma forma de apelo à ajuda da família e da sociedade, ou de excessiva preocupação em resguardar a família de transtornos. Citamos acima a visão tripartite da autonomia: a capacidade de tomada de decisão, a informação adequada e uma escolha voluntária (GATHER; VOLLMANN, 2013; HUGHES et. al., 2010). Num sentido parecido, Beauchamp e Childress sugerem analisar-se "a ação autônoma em termos dos agentes normais que agem (1) intencionalmente, (2) com entendimento e (3) sem influências controladoras que determinem a [sua] ação".

Também se sugere que a avaliação de capacidade não seja feita apenas uma vez, mas em momentos distintos, pois a capacidade do paciente pode variar de situação para situação, podendo não ser capaz para algumas decisões e capaz para outras, o grau de capacidade pode flutuar 
ao longo do dia e um parecer num momento específico dos cuidados não significa automaticamente incapacidade, por exemplo, no caso de demência (GATHER; VOLLMANN, 2013; BEAUCHAMP; CHILDRES, 2013). Por outro lado, à medida que doenças degenerativas ou mentais progridem mal, a capacidade de decisão vai sendo progressivamente cada vez mais comprometida e enfraquecida. Isso ressalta a importância do diagnóstico precoce, para que o paciente possa tomar as melhores decisões para si, incluindo preparar, por exemplo, documento legal com diretrizes antecipadas de vontade, onde essa possibilidade existe.

Uma avaliação da capacidade consistiria, em algumas visões, em considerar critérios como: compreender informações recebidas e reproduzila com suas próprias palavras; ser capaz de fazer e expressar uma escolha; conseguir analisar $o$ adoecimento e o benefício ou malefício das intervenções médicas ou de cuidado; processar racionalmente a informação médica fornecida, colocando-a no contexto de sua própria vida; avaliar as consequências previsíveis e ponderar sobre as alternativas disponíveis (BEAUCHAMP; CHILDRES, 2013). Gather e Vollmann (2013) identificaram testes objetivos de avaliação de competência que tendiam a apresentar o resultado de incapacidade em maior frequência que os testes clínicos. Uma possível razão é que eram excessivamente quantitativos e cognitivos, deixando em segundo plano aspectos como: fatores emocionais, contextuais, críticos e subjetivos. Isso sugere que as avaliações aconteçam de forma complementar, com estratégias variadas envolvidas, como testes, entrevistas, visitas, observações e que mais de um avaliador esteja envolvido em momentos distintos (GALBRAITH; DOBSON, 2000; RAIJMAKERS et al., 2018).

Os níveis da decisão parecem ser de fato variados, o que sugere que os níveis de habilidade para se medir a capacidade também o sejam, e é nesse sentido que Beauchamp e Childress (2013) alertam para o contexto da decisão e para que se busque promover as capacidades de decisão autônoma. Ao invés de se chegar a uma resposta taxativa do tipo "capaz" ou "incapaz", poderia haver uma estratégia de escala móvel, em que quanto maior o risco, mais alta a exigência de capacidades, ou, para evitar restringir em demasia a autonomia, alguma combinação de estratégias.

A habilidade de uma pessoa para tomar decisões pode ser influenciada por uma queda em sua habilidade de aceitar as informações que Ihes são passadas, por exemplo, mecanismos psicológicos de defesa alteram a capacidade de julgamento de uma pessoa sobre uma determinada situação (BEAUCHAMP; CHILDRESS, 2013). Nos mecanismos de negação, por exemplo, o paciente, como forma de se proteger, e para não ter que lidar com o sofrimento, nega-o, como se ele não existisse (KÜBLER-ROSS, 
2008). O auxílio psicológico é muito importante para dar suporte ao enfrentamento da realidade do diagnóstico. No caso de pacientes críticos, uma parte importante do zelo pelas capacidades de decidir do paciente está em informar devidamente sobre o prognóstico, sobre as possibilidades de cuidado que proporcionam, em muitos casos, boa qualidade de vida, bem como sobre o direito do paciente de não se submeter às terapêuticas que não julgar conveniente, o direito de recusar tratamento (GATHER; VOLLMANN, 2013; GALBRAITH; DOBSON, 2000).

Na tentativa de compreender por que algumas pessoas com câncer e com depressão desejam antecipar a morte, enquanto outras não, um estudo (AKECHI et al., 2001) evidenciou que a gravidade da Depressão e do funcionamento físico são os principais fatores que contribuem para esse desejo, e uma revisão (GUY; STERN, 2006) identificou a Depressão como fator central para o desejo de morrer. Isso sugere presença de um tipo especial de vulnerabilidade, na Depressão, influenciando especialmente aquilo que mais importa na justificação do suicídio clinicamente assistido e na eutanásia voluntária, ou seja, a capacidade de decidir livre e de modo bem informado. A Depressão Maior é muitas vezes um fator de ausência ou diminuição significativa da capacidade de decidir. Muitas pessoas pedindo ajuda para morrer podem estar sob a influência de um transtorno mental maior que aumentou sua vulnerabilidade 4 .

Por outro lado, pode ser que, ao se analisar os casos individualmente, haja aqueles pacientes que estejam, e aqueles que não estejam demasiadamente influenciados pela Depressão como o fator significativo no desejo de morrer, ou de se retirar de um tratamento, ou de participar de pesquisas arriscadas. Transtornos mentais e em especial a Depressão Maior parecem ser fortes fatores de alerta em relação a quando a vulnerabilidade afeta a capacidade de decidir. A Depressão Maior é tanto um alerta contra incluir rapidamente pessoas com tal transtorno em protocolos arriscados de terapia ou pesquisa, assim como, por outro lado, um alerta contra tornar o diagnóstico de transtorno mental razão para automaticamente considerar alguém como totalmente incapaz e fora de cogitação para estes protocolos. Assim, avaliação cuidadosa (com aplicação de entrevistas, testes psicológicos e cuidados psicológicos) funcionaria para diminuir os dois riscos (GEORGE, 2016), embora não se deva cair no autoritarismo da avaliação psicológica que enquadre ou assuma que, com a avaliação, se está demonstrando completamente qual o quadro do paciente: ela é necessária, porém limitada, especialmente com o conhecimento e tecnologia disponíveis hoje. É por esses limites que se sugere, como apresentado, mais que a avaliação psicológica, mas o cuidado psicológico como processo que 
oportuniza espaço para que o paciente possa melhor se conhecer e tomar suas decisões, inclusive, apesar de seu quadro diagnóstico.

Segundo Pelbart, "a saúde não é só a capacidade de evitar catástrofes, mas também a de criar novas normas arriscando a própria vida" (PELBART, 2009), e a vida não pode estar baseada totalmente da noção de defender-se. Há também a negociação de sua expansão, potencializando novas possibilidades. Isso nos distancia, na visão de Pelbart, da concepção de saúde como estabilidade. Nesse sentido, pode-se considerar que o conceito de cura é problemático: a palavra poderia carregar em si a noção de completa oposição à doença ou justamente a noção de completa estabilidade. Numa visão fenomenológico-existencial, por exemplo, entende-se que a saúde e a doença são etapas de um mesmo processo de existir. Sendo assim e sabendo que os momentos que chamamos de crise às vezes são distanciados em intervalos de anos, um paciente que sai de um tratamento bem-sucedido, que foi devidamente acompanhado com as terapêuticas disponíveis e manifestando qualidade de vida, poderia afirmar autonomamente sua decisão sobre tratamentos e pesquisas futuras? Esse é um desafio difícil de ser enfrentado e não sabemos ainda o que pensar do uso de tal estratégia para avaliar propostas de pesquisas com pessoas com transtornos mentais maiores.

O paciente poderia ou deveria sair quantas vezes de uma situação que estamos chamando de crise? E formulando essa pergunta, acrescentando a dimensão do desejo, um paciente poderia desejar sair quantas vezes de uma situação crítica? Provavelmente essa resposta tem relação com as condições disponíveis para se viver. Em psicoterapia procuramos pontos de conexão entre o paciente e aquilo que lhe oferece sentido e vontade de viver, mas considerando casos em que já temos anos com as terapêuticas oferecidas e um longo histórico de reincidência e talvez perdas sociais importantes (como no caso de idosos), retomamos uma pergunta estabelecida por Silva (2015): qual vida estamos querendo defender?

Ainda sobre os pacientes como sujeitos vulneráveis, é bastante significativa, nos estudos sobre a perspectiva dos próprios pacientes e familiares, que eles parecem ter uma intuição da dignidade como algo de sua vivência subjetiva, como bem-estar e autocontrole, e não como algo externo ou diferente disto, como seria com um conceito filosófico ou religioso acerca do valor dos seres humanos como pessoas, separado de tais correlatos subjetivos. Uma questão em bioética é se dignidade e valor não aparecem, aos olhos dos pacientes, como algo intimamente relacionado à própria decisão pessoal e ao respeito que os outros lhes devem, algo em 
geral evidenciado também em pesquisas descritivas (com questionários) sobre qualidade de vida (PANZINI et. al., 2007).

Nesta perspectiva reforça-se, e pelos próprios afetados, uma teoria do respeito pela autonomia como equivalente à teoria da dignidade da pessoa humana, ou, ao menos, como parte necessária desta segunda, que, no nosso entender, não pode, sem outras evidências e razões, apoiar a recusa da vontade do paciente em aderir ou recusar terapias ou pesquisas, como coisas contrárias à dignidade humana por si mesmas. Mesmo sobre viver e morrer, no caso do suicídio assistido, o bem é algo mais importante do que simplesmente se estar ou se manter vivo, quando as pessoas já não identificam estar nesta vida como parte do seu bem, ou sem desejar tal manutenção da vida (COYLE; SCULCO, 2004; DIERICKX; DELIENS; COHEN; CHAMBAERE, 2016; SILVA, 2015). Com transtornos mentais maiores algo disso poderia ser o caso? Pensamos que sim, ainda que mais estudos e aprofundamentos sejam necessários e bem-vindos para esclarecer-se melhor isso.

\section{Considerações Finais}

A exposição e análise organizadas e elaboradas acima sugerem que a inter-relação entre a vulnerabilidade mental e capacidade de decisão racional é complexa e ocorre nos dois sentidos: nem as pessoas sem transtornos mentais são, de fato, significativamente autônomas e isentas de dificuldades para tomada de decisão livre e esclarecida, nem aquelas que estejam acometidas de transtornos mentais são, independentemente do tipo e do grau de seu transtorno, e também de sua capacidade cognitiva individual no momento da decisão, totalmente sem autonomia e sem capacidades de decidir de modo esclarecido. Isso deve alertar a todos que os aspectos éticos das pesquisas com seres humanos vulneráveis, como o consentimento que possam dar, os cuidados relacionados com sua vulnerabilidade (como o apoio extra de cuidadores ou tutores) e a minimização de riscos ao bem-estar dos participantes, tem de ser constantemente revistos à luz de como tal inter-relação se desenvolve. Modos variados de pesquisa com pessoas com depressão são eticamente mais ou menos aceitáveis na medida em que compreendermos melhor a sua vulnerabilidade como impedimento à capacidade de entendimento e de decisão racional, e na medida do impacto da pesquisa sobre o bem-estar do indivíduo pesquisado. Os aspectos factuais e éticos destacados no trabalho, porém, são uma exploração inicial e precisam ser estudados com maior aprofundamento; a relação entre transtornos mentais e capacidades de decisão deve ser acompanhada mais de perto através da literatura 
neurocognitiva e neuroética em expansão; estudos empíricos sobre pesquisas que envolveram pessoas com transtornos mentais devem ser considerados com maior cuidado em outros estudos. 


\section{Notas}

1 Professor do Instituto de Filosofia (IFILO) da Universidade Federal de Uberlândia (UFU), pesquiso e leciono na Graduação em Filosofia, no Programa de Pós-Graduação em Filosofia (Mestrado), e no Programa de Pós-Graduação em Ciências da Saúde (Mestrado e Doutorado). Trabalho nas seguintes áreas: metaética, ética normativa, ética prática, bioética, filosofia da biologia, filosofia da mente. Pesquiso e me interesso pelos seguintes assuntos: racionalidade, normatividade, naturalismo, valor da vida, ética na pesquisa (com embriões, fetos, animais, crianças, esportistas), aborto, infanticídio, eutanásia, melhoramento humano, saúde pública, pobreza, mudança climática. Também me interessam estudos empíricos sobre placebo, comparação de tratamentos com e sem uso de drogas, bem-estar animal, absorção de vitamina B12, dietas, consentimento presumido, doação de órgãos, FIV. Sou membro da International Society of Bioethics (IAB), da Sociedade Brasileira de Bioética (SBB), do Núcleo de Estudos do Pensamento Contemporâneo (UFMG/Fapemig), e pesquisador do CNPq (Conselho Nacional de Desenvolvimento Científico e Tecnológico Produtividade em Pesquisa). ORCID-iD: https://orcid.org/0000-0002-7910-6961; email: abonella@ufu.br

2 Psicóloga clínica, doutora em Ciências da Saúde, professora da Universidade do Estado de Minas Gerais (UEMG), Ituiutaba, Minas Gerais (M.G). É co-fundadora da clínica Margem da Palavra e idealizadora do Circuito Básico de Formação em Acompanhamento Terapêutico. Pesquisa e trabalha a partir da perspectiva existencialhumanista, com interesse especial por qualidade de vida e qualidade de morte. ORCIDID: $\quad$ https://orcid.org/0000-0001-5554-7191;

gabrielafrancoalmeida@hotmail.com

e-mail:

3 Professor Associado II do Instituto de Filosofia e do Programa de Pós-graduação em Filosofia da Universidade Federal de Uberlândia (UFU), Uberlândia, Minas Gerais (M.G.). Doutor e Mestre em Filosofia pelo Programa de Pós-Graduação em Filosofia da Universidade Federal do Rio de Janeiro (UFRJ). Bacharel em Filosofia pela Universidade Federal do Rio de Janeiro (UFRJ). Professor Associado II do Instituto de Filosofia e do Programa de Pós-graduação em Filosofia da Universidade Federal de Uberlândia (UFU), Uberlândia, Minas Gerais (M.G.). Atua na área de Filosofia da Mente, Filosofia da Psicologia e Filosofia das Neurociências. ORCID-iD: http://orcid.org/0000-0002-97775667; e-mails: umamenteconsciente@gmail.com e leonardoferreiraalmada@ufu.br

${ }^{4}$ A principal diferença entre o chamado transtorno depressivo persistente (distimia) e o transtorno depressivo maior é, segundo o DSM-V (2013, p. 155), "a presença de humor triste, vazio ou irritável, acompanhado de alterações somáticas e cognitivas que afetam significativamente a capacidade de funcionamento do indivíduo". A distinção é sobretudo da ordem de "aspectos de duração, momento ou etiologia presumida" (DSM-V, 2013, p. 155). O transtorno depressivo maior representa a condição clássica do grupo dos transtornos depressivos, sendo marcado por episódios distintos de pelo menos duas semanas de duração, posto que, na maior parte das vezes, os episódios durem um tempo significativamente maior. O transtorno depressivo maior é de relevância para as finalidades dessa pesquisa por envolver alterações nítidas "no afeto, na cognição e em funções neurovegetativas, e remissões interepisódicas", ao passo que a forma mais crônica de depressão é sobremaneira caracterizada por uma persistente perturbação de humor. 


\section{Referências bibliográficas}

AKECHI, Tatsuo; OKAMURA, Hitoshi; YAMAWAKI, Shigeto; UCHITOMI, Yosuke. Why do some cancer patients with depression desire na early death and others do not? Psychosomatics, v. 42, n. 2, p. 141-145, 2001.

AMERICAN PSYCHIATRIC ASSOCIATION. DSM-IV. Manual Diagnóstico e Estatístico de Transtornos Mentais. 4a . ed. Porto Alegre, RS: ARTMED, 2002.

AMERICAN PSYCHIATRIC ASSOCIATION. DSM-V. Diagnostic and Statistical Manual of Mental Disorders. 5a ed. Arlington, VA: American Psychiatric Association, 2013.

BEAUCHAMP, Tom. The Principle of Beneficence in Applied Ethics. In: ZALTA, Edward N. The Stanford Encyclopedia of Philosophy (Spring 2019 Edition).

Disponível em:

$<$ https://plato.stanford.edu/archives/spr2019/entries/principlebeneficence/>. Acesso em 07 mar. 2021.

BEAUCHAMP, T. L. \& CHILDRESS, J. F. Principles of Biomedical Ethics. Oxford, Oxford University Press, 2013.

BLEULER, Eugen. Dementia praecox, or the group of Schizophrenias. New York, NY: International University Press, 1911.

BONELLA, Alcino Eduardo. A ética dos testes clínicos de desafio humano na avaliação de vacinas e tratamentos para a COVID-19. In: TAUCHEN, Jair; CASTANHEIRA, Nuno; OLIVEIRA, Nythamar de. (Org.) Bioethics \& neuroethics in global pandemic times. (pp. 15-30). Porto Alegre, RS: Fundação Fênix, 2020.

BORTOLOTTI, Lisa. Rationality and sanity: the role of rationality judgments in understanding psychiatric disorders. In: FULFORD, K. W. M.; DAVIES, Martin; GIPPS, Richard G. T.; GRAHAM, George; SADLER, John Z.; STANGHELLINI, Giovanni; THORNTON, Tim. The Oxford Handbook of Philosophy and Psychiatry (p. 480-496). Oxford, UK: Oxford University Press, 2013.

BREGGIN, Peter Roger. Psychotherapy as applied ethics. Psychiatry, v. 34, p. 59-74, 1974.

BREGGIN, Peter Roger. Psychiatry and psychotherapy as political processes. American Journal of Psychotherapy, v. 29, 369-382, 1975. 
BUSS, Sarah; WESTLUND Andrea. Personal Autonomy. In: ZALTA, Edward (ed.). The Stanford Encyclopedia of Philosophy (Spring 2018 Edition). Disponível em: $<$ https://plato.stanford.edu/archives/spr2018/entries/personalautonomy/>. Acesso em 22 fev. 2021.

CORDEIRO, Franciele Roberta. Eu Decido o Meu Fim? A mídia e a produção de sujeitos que governam a sua morte. Dissertação (Mestrado em Enfermagem) - Programa de Pós-Graduação em Enfermagem da Universidade Federal do Rio Grande do Sul. Porto Alegre, RS: Universidade Federal do Rio Grande do Sul, 160 f. 2013.

COYLE, Ness; SCULCO, Louis. Expressed desire for hastened death in seven patients living with advanced cancer: a phenomenologic inquiry. Oncology Nursing Forum, v. 31, n. 4, p. 699-709, 2004.

DIERICKX, Sigrid; DELIENS, Luc; COHEN, Joachim; CHAMBAERE, Kenneth. Euthanasia in Belgium: trends in reported cases between 2003 and 2013. CMAJ, v. 188, n. 16, p. 407-414, 2016.

GALBRAITH, Kim M; DOBSON, Keith. The role of the psychologist in determining competence for assisted suicide/euthanasia in the terminally ill. Canadian Psychology, v. 41, n. 3, p. 174-183, 2000.

GEORGE, Constance E. When Is Depression a Terminal Illness? deliberative suicide in chronic mental illness. AMA Journal of Ethics, v. 18, n. 6, p. 594600,2016 .

GRISSO, Thomas; APPELBAUM, Paul S. Assessing Competence to Consent to Treatment: A guide for Physicians and Other Health Professionals. New York, NY: Oxford University Press, 1998.

GUY, Maytal; STERN, Theodore A. The Desire of Death in the Setting of Terminal Illness: a case discussion. Primary Care Companion to The Journal of Clinical Psychiatry, v. 8, n. 5, p. 299-305, 2006.

HINDMARCH, Thomas; HOTOPF, Matthew; OWEN, Gareth S. Depression and decision-making capacity for treatment or research: a systematic review. BMC Med Ethics, v. 14, n. 54, p. 1-10, 2013.

NYS, Thomas. Autonomy, Trust and Respect. The Journal of Medicine and Philosophy, v. 41, n. 1, p. 10-24, 2016.

EDWARDS, Rem Blanchard (1981). Mental health as rational autonomy. Journal of Medicine and Philosophy, v. 6, n. 3, p. 309-322, 1981. 
EDWARDS, Rem Blanchard (Ed.). Ethics and Psychiatry: Insanity, Rational Autonomy, and Mental Health Care. 2a ed. Amherst, New York: Prometheus Books, 1997 [1982].

ENGELHARDT Jr., Hugo Tristam. Psychotherapy as meta-ethics. Psychiatry, v. 36, p. $440-445,1973$.

FINGARETTE, Herbert. Insanity and responsibility. Inquiry, v. 15, p. 6-29, 1972.

GATHER, Jakov; VOLLMANN, Jochen. Physician-assisted suicide of patients with dementia: a medical ethical analysis with a special focus on patient autonomy. International Journal of Law and Psychiatry, v. 36, n. 5-6, p. 444-453, 2013.

HUGHES, Jonathan; HUNTER, David; SHEEHAN, Mark; WILKINSON, Stephen; WRIGLEY, Anthony. European Textbook on Ethics in Research. Luxembourg: Publications Office of the European Union; 2010

KLÜBER-ROSS, Elisabeth. Sobre a morte e o morrer. São Paulo, SP: Martins Fontes; 2008.

MEYNEN, Gerben. Free will and mental disorder: exploring the relationship. Theoretical medicine and Bioethics, v. 31, n. 6, p. 429-443, 2010.

MOORE, Michael S. Some myths about "Mental illness"'. Archives of General Psychiatry, v. 32, p. 1483-1497, 1975.

PANZINI, Raquel Gehrke; ROCHA, Neusa Sicca da; BANDEIRA; Denise Ruschel FLECK, Marcelo Pio de Almeida. Qualidade de vida e espiritualidade. Revista de Psiquiatria Clínica, v. 34, n. 1, p. 105-115, 2007.

PELBART, Peter Pál. Da clausura do fora ao fora da clausura: loucura e desrazão. São Paulo, SP: Iluminuras, 2009.

RADDEN, Jennifer. Mental Disorder (Illness). In: ZALTA, Edward (ed.). The Stanford Encyclopedia of Philosophy (Winter 2019 Edition). Disponível em: <https://plato.stanford.edu/archives/win2019/entries/mental-disorder>. Acesso em 22 fev. 2021.

RADOILSKA, Lubomira (Ed.). Autonomy and Mental Disorder. Oxford, UK: Oxford University Press, 2012.

RAIJMAKERS, Natasja Johanna Helana; HEIDE, Agnes van der; KOUWENHOVEN, Pauline S. C.; van THIEL, Ghislain; van DELDEN, Joahnes J; Rietjens, JUDITH A. C. Assistance in dying for older people without a 
serious medical condition who have a wish to die: a national cross-sectional survey. Journal of Medical Ethics, v. 41, n. 2, p. 145-150, 2015.

RATCLIFFE, Matthew. Depression and the phenomenology of free will. In: In: FULFORD, K. W. M.; DAVIES, Martin; GIPPS, Richard G. T.; GRAHAM, George; SADLER, John Z.; STANGHELLINI, Giovanni; THORNTON, Tim. The Oxford Handbook of Philosophy and Psychiatry. Oxford, UK: Oxford University Press, 2013, p. 574-591.

SADLER, John Z.; FULFORD, K. W. M.; van STADEN, Cornelius Werendly (eds.). The Oxford Handbook of Psychiatric Ethics. Oxford, UK: Oxford University Press, 2015.

SILVA, Luiz Felipe da Cunha e. Crônica de uma morte adiada: o tabu da morte e os limites não científicos da ciência. Revista Bioética, v. 23, n. 2, p. 331-339, 2015.

SZASZ, Thomas. Insanity: the idea and its consequence. Syracuse, NY: Syracuse University Press, 1997.

WALTER, Henrik. Neurophilosophy of free will: From libertarian illusions to a concept of natural autonomy. Cambridge, MA: MIT Press, 2001. 